\title{
WEB-Based Intelligent Diagnosis System for Cotton Diseases Control
}

\author{
Hui $\mathrm{Li}^{1}$, Ronghua $\mathrm{Ji}^{2}$, Jianhua Zhang ${ }^{1}$, Xue Yuan ${ }^{1}$, Kaiqun $\mathrm{Hu}^{1}$, and Lijun Qi ${ }^{1, *}$ \\ ${ }^{1}$ College of Engineering, China Agriculture University, Beijing, P.R. China, 100083 \\ Tel.: +86-010-62736164 \\ qilijun@cau.edu.cn \\ ${ }^{2}$ College of Electric and Information Engineering, China Agriculture University, \\ Beijing, P.R. China, 100083
}

\begin{abstract}
Diseases control is always an issue in cotton production, the timely detection and effective control of diseases depend on, in most cases, an effective diagnosis system. Based on the distribution of cotton diseases in the main yielding areas of China in recent years, the main species and characters of cotton diseases were listed classified in the study and a database was established for this purpose. BP neural network as a decision-making system was used to establish an intelligent diagnosis model. Based on the model, a WEB-based Intelligent Diagnosis System for Cotton Diseases Control was developed. An experiment scheme was designed for the system test, in which 80 samples, including 8 main species of diseases, 10 samples in each sort were included. The result showed the rate of correctness that system could identify the symptom was $89.5 \%$ in average, and the average running time for a diagnosis was $900 \mathrm{~ms}$.
\end{abstract}

Keywords: Cotton, Diseases, Intelligent Diagnosis System.

\section{Introduction}

Cotton is playing a crucial role in the national agricultural economy of China. Cotton diseases and insects are the two main causes of damage on both quantity and quality of the cotton production. A timely detection of the pests and feasible controlling measures are cure to the effective cotton protection.

The researches concerning disease diagnosis systems for agricultural products started from the late seventies of the last century. The first disease diagnosis system, the soybean disease diagnosis expert system (Plandds), was developed by the University of Illinois (1978). Some additional work, the integrated expertise system for soybean pest control (SOYBUG) [6], the expertise system for orchard management and pest control (POMME) were developed in the state of Florida. Japan has also conducted a lot of researches on disease diagnosis [3-5]. Comax-Cossym (Cotton Production

\footnotetext{
* Corresponding author.
} 
Management System) developed by the Crop Simulation Center from Agricultural Research Service in the United States Department of Agriculture (USDA) is the most successful agricultural expertise system in the world, which improved the U.S. cotton production management [9-10] significantly.

The related researches in China are developing rapidly since last eighties. The Cotton Pests Management Expertise Decision Support system (COPMEDS) developed by the Institute of Zoology at Chinese Academy of Science was in the leading place [11]. Liang and Shi (1997) developed a cotton pest diagnostic system based on the BP neural network, which enhanced the running speed of the system by simplifying the neural network model [13]. Jiang et al. (1998) developed the Prototype of rule-based cotton pest management expert system by utilizing the expertise system development tool KA3 [14]. Zhang et al. (2005) designed the knowledge-model-based decision support system for cotton management .This system used system analysis and mathematical modeling to solve the issue of the overly-spread information in a huge knowledge data base, enabling decision-making processes to be more rapidly and simplified [15]. Wang et al. (2008) designed a cotton fertilization expertise system based on Geographical Information System (GIS) in XinJiang. The system presented extensive research and discussion on the application of GIS technology to cotton fertilization expertise system [16]. Liu, etc. (2009) designed a Web-GIS-based expertise system to forecast agricultural diseases and pests [17].

The work presented in this paper is based on the description of the pattern of the cotton diseases, and the identification of the type and characteristic of the major disease problems during the recent years in China. A Cotton Disease Intelligent Diagnosis and Decision Model was established, and a WEB-based Intelligent Diagnosis System for Cotton Diseases Control was developed with the BP neural network as the decision support system.

\section{System Overview}

The yield and the quality of cotton are affected significantly by the disease, which means farmers' great financial loss. As the lack of basic knowledge of cotton diseases detection and protection, the cotton farmers are longing for the guidance from experts since the occurrence of new and large variety of diseases. However, such experts are not always available for the emergencies. A diagnosis system is therefore considered effective in helping cotton farmers.

A Web-based Intelligent Diagnosis System for Cotton Diseases Control could realize the querying, diagnosing and online consulting of the main diseases during the whole growing process. Multiple users could access the system simultaneously. The system also could facilitate experts to input, update, modify and search data, information and rules associated with cotton intelligent diagnosis system knowledge and database.

Web-based Intelligent Diagnosis System for Cotton Diseases Control was consisted of four separate modules: Query module, Diagnosis module, Management module, and Expert online. The scheme of the system is shown as figure 1. 


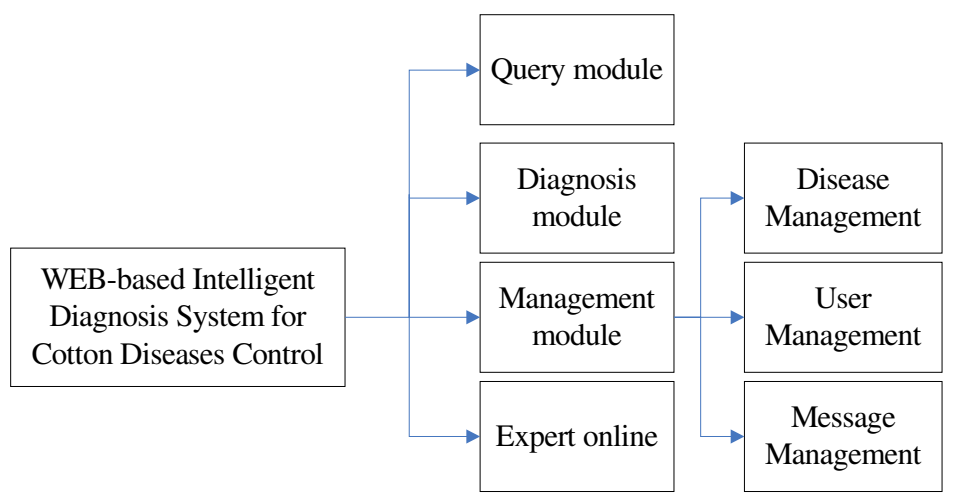

Fig. 1. Scheme of the system function

Where:

1. Query module: information could be queried from the cotton disease database by the keywords imputed in the query interface by users.

2. Diagnosis module: inference engine of the system provided diagnosis results and corresponding control methods by the disease factors chosen by users in the diagnosis interface.

3. Management module: serviced for the system back-stage management, which was divided into three parts: disease management, message management and user management.

4. Expert online: the communication bridge between experts and users.

\section{System Design}

The system was a three-layer model with "data layer / application layer / interface layer". Where: Data layer was the bottom layer of the system, which was used for the storage of information needed by the system, and was consisted of database and knowledge base. Database was used to store the basic facts of cotton disease, description of problems, intermediate and final results during the diagnostic process, etc. Knowledge base was used to store knowledge and experience of cotton disease experts.

Application layer which included Web inference engine and application server could realize the inference and explanation functions of the system diagnosis. The BP neural network technology was used to execute the knowledge inference and diseases diagnosis based on the symptoms supplied by users.

Interface layer enabled the interaction of users and system. There were two types of users, ordinary and administrator, in the system. Ordinary users could query disease and input the required information by selecting disease factors, and the disease diagnosis and appropriate control methods were given to users in the form of interface. Administrator users managed the knowledge base and database. 
The structure of cotton intelligent diagnosis system is shown in figure 2 .

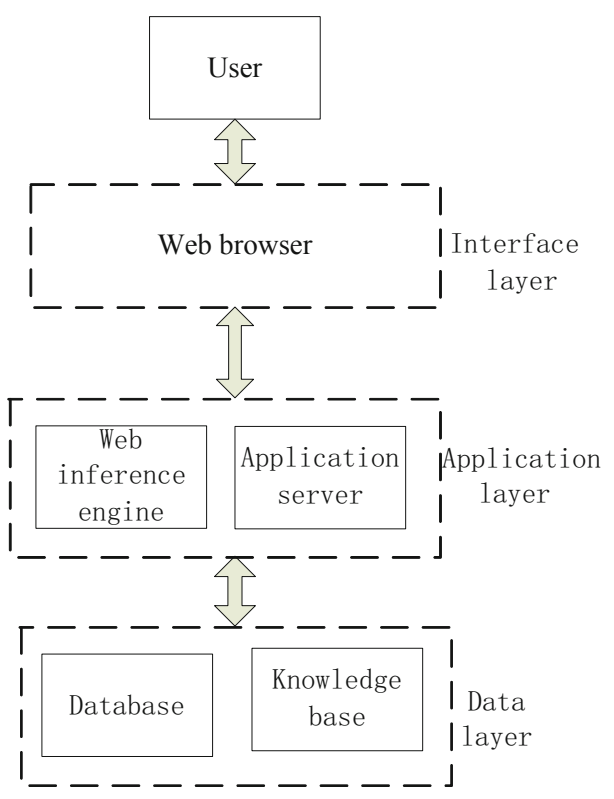

Fig. 2. Structure of cotton intelligent diagnosis system

\subsection{Cotton Disease Database}

The database designed in this paper included the disease table, disease picture table, user table and message table, which has played an important role in the development of Intelligent Diagnosis System for Cotton Diseases Control.

The structure of diseases table is as follows:

Table 1. Structure of disease table

\begin{tabular}{cccc}
\hline List & Data Type & Non-empty & Notes \\
\hline dis_id & Int & Yes & Keyword \\
name & Varchar(20) & Yes & Name \\
region & Varchar(80) & No & $\begin{array}{c}\text { Geographical } \\
\text { place }\end{array}$ \\
& & & Pathogen \\
Pathogen & Varchar(160) & No & Occurrence \\
law & Varchar(1000) & No & Control \\
prevention & Varchar(1000) & No & methods \\
& & & Germ \\
\hline
\end{tabular}




\subsection{Knowledge Base of Cotton Diseases}

Knowledge base was used to store basic knowledge and practical experience of cotton disease experts. Based on the investigation of the occurrence and the distribution of cotton diseases in recent years, there were more than 20 kinds of main cotton diseases in the main yielding areas of China. 8 kinds of diseases as the major disease of cotton were identified, such as, Cotton anthracnose, Cotton damping-off, Cotton Red rot disease and Cotton wilt, etc. Based on the analysis and summary of cotton disease symptoms, 5 categories and 32 symptoms were summarized, and which were numbered, so that each symptom of each category corresponded to a number.

Table 2. Cotton disease factor

\begin{tabular}{|c|c|c|c|c|c|c|c|c|c|}
\hline \multicolumn{2}{|c|}{ Diseases period } & \multicolumn{2}{|c|}{ Disease location } & \multicolumn{2}{|c|}{ Lesion shape } & \multicolumn{2}{|c|}{ Lesion color } & \multicolumn{2}{|c|}{ Lesion state } \\
\hline Factor & Symptom & Factor & Symptom & Factor & Symptom & Factor & Symptom & Factor & Symptom \\
\hline a1 & $\begin{array}{l}\text { Seeding } \\
\text { stage }\end{array}$ & b1 & Cotyledons & $\mathrm{c} 1$ & $\begin{array}{l}\text { Semi-circular } \\
\text { or circular }\end{array}$ & d1 & Brown & e1 & Dot \\
\hline $\mathrm{a} 2$ & Bud stage & $\mathrm{b} 2$ & Stem & c2 & Near circle & d2 & Dark brown & $\mathrm{e} 2$ & Water stains \\
\hline \multirow[t]{8}{*}{ a3 } & Boll stage & b3 & Leaf & c3 & Irregular & d3 & Red-brown & e3 & Grease-like \\
\hline & & b4 & Boll & $\mathrm{c} 4$ & Polygon & $\mathrm{d} 4$ & Tan & e4 & $\begin{array}{l}\text { Physalospora } \\
\text { black Dots }\end{array}$ \\
\hline & & & & $\mathrm{c} 5$ & Spindle & d5 & Pink & e5 & Slime \\
\hline & & & & & & d6 & Yellow & e6 & Mold, Floc \\
\hline & & & & & & d7 & $\begin{array}{l}\text { Dark green, } \\
\text { black }\end{array}$ & e7 & $\begin{array}{l}\text { Fold } \\
\text { Withered }\end{array}$ \\
\hline & & & & & & $\mathrm{d} 8$ & Gray, white & e8 & Mycelium \\
\hline & & & & & & d9 & Deep blue & e9 & $\begin{array}{l}\text { Dwarf, } \\
\text { Withered }\end{array}$ \\
\hline & & & & & & d0 & Dark red & $\mathrm{e} 0$ & $\begin{array}{l}\text { Color } \\
\text { changed, } \\
\text { Reticulated }\end{array}$ \\
\hline
\end{tabular}

Based on the diseases factors listed in table 2, the factors corresponding to different diseases and the causalities of diseases were listed in the diseases table.

\subsection{Inference Engine of Cotton Diseases}

The core of the cotton disease diagnosis system was the inference engine. Most of the existing reasoning models carried out the forward and backward reasoning by constructing a database of disease recognition features and using a standard query language 
Table 3. Disease

\begin{tabular}{|c|c|c|c|c|c|}
\hline Name & $\begin{array}{l}\text { Diseases } \\
\text { period }\end{array}$ & $\begin{array}{l}\text { Disease } \\
\text { location }\end{array}$ & $\begin{array}{l}\text { Lesion } \\
\text { shape }\end{array}$ & $\begin{array}{l}\text { Lesion } \\
\text { color }\end{array}$ & $\begin{array}{l}\text { Lesion } \\
\text { state }\end{array}$ \\
\hline Cotton anthracnose & a1 a 2 a3 & b1 b2 b3 b4 & $\mathrm{c} 1 \mathrm{c} 2 \mathrm{c} 5$ & $\mathrm{~d} 2 \mathrm{~d} 8 \mathrm{~d} 0$ & e4 e 5 \\
\hline Cotton Rhizoctonia & a1 a2 & b1 b2 b3 & c3 & $\mathrm{d} 1 \mathrm{~d} 4 \mathrm{~d} 6$ & e 7 e 9 e 0 \\
\hline Cotton boll rot disease & a1 a3 & $\mathrm{b} 1 \mathrm{~b} 2 \mathrm{~b} 4$ & $\mathrm{c} 1$ & $\mathrm{~d} 1 \mathrm{~d} 5$ & e6 e7 \\
\hline Cotton Hongfen disease & a1 a3 & b1 b4 & $\mathrm{c} 1$ & $\mathrm{~d} 1 \mathrm{~d} 5$ & e6 \\
\hline Cotton wilt & a1 & b1 & & d6 & $\mathrm{e} 0$ \\
\hline Cotton phytophthora boll rot & a1 a3 & b1 b4 & & $\mathrm{d} 7 \mathrm{~d} 8$ & $\mathrm{e} 2 \mathrm{e} 8$ \\
\hline Cotton angular leaf spot & a1 a2 & b1 b2 b3 & $\mathrm{c} 4$ & $\mathrm{~d} 7$ & e3 \\
\hline Cotton damping-off & a1 a3 & b2 b4 & $\mathrm{c} 1$ & $\mathrm{~d} 1 \mathrm{~d} 6 \mathrm{~d} 8$ & e2 e 6 e 7 \\
\hline
\end{tabular}

(SQL). The process of knowledge acquisition and mimic expert reasoning for these models has grown an over-reliance on expert knowledge and experience, the practicality was poor and also with limitations.

Neural network was a massively parallel processing and self-learning, self- organizing, nonlinear dynamic system, which was particularly suited to complex non- deterministic causal reasoning, judging, identification, and classification problems. It had the self-learning function and cuold constantly enrich the content of the knowledge base. Therefore, BP neural network was used as the inference engine of cotton diseases in this system.

BP neural network was constructed as a disease inference engine based on the analysis and summary of cotton disease symptoms. There were 32 input nodes which were corresponding to 32 diseases in the BP neural network. According to empirical formula $N=\sqrt{m n}$, the number of nodes $N$ in the hidden layer was obtained as $N=16$. Then by errors comparison, the optimal number of neurons in the hidden layer was determined.

There were 8 output nodes which were corresponding to 8 major diseases of cotton. The BP neural network was trained and validated by using Matlab in the article. The hidden layer transfer function was s-type tangent function tansig, the output layer transfer function was purelin, and the training method was Levenberg-Marquardt with the training function trainlm. Gradient descent momentum learning function learngdm was used as the learning function, and the performance function was mse. 
By experimental verification of the system with 8 kinds of diseases (each with 10 samples), the average diagnostic accuracy was $89.5 \%$ and the average diagnosis time was $900 \mathrm{~ms}$.

\section{Conclusion}

A web-based intelligent diagnosis system for cotton diseases control was developed in this article. Based on the research of cotton disease occurrence in recent years and on the analysis of the cotton diseases characteristics, a corresponding database was established and disease factors for the description of various diseases were obtained then. BP neural network combined with the Web technology was used as the disease inference engine in the system, so that the diagnostic accuracy and intelligence as well as the ability to solve the uncertain and ambiguous problems were enhanced. Modelling results showed that the diagnosis system was high-accuracy and high-speed. The system was effective and easy to operate with the friendly interface. It was expected to show the high feasibility to the field situation by more practical tests.

\section{Acknowledgements}

We would like to thank Kaiqun $\mathrm{Hu}$ and Jianhua Zhang for their technical assistance. We would also like to acknowledge Ronghua Ji for her valuable suggestions on the improvement of the system.

\section{References}

1. An, G.M., Xu, S.Y., Zhao, C.: Foreign Facilities Situation and Development Trend of Agriculture. J. Modern Agriculture 12, 34-36 (2004) (in Chinese)

2. Rafea, A., Hassen, H., Hazman, M.: Automatic Knowledge Acquisition Tool for Irrigation and Fertilization Expert Systems. J. Expert Systems with Applications 24, 49-57 (2003)

3. Grove, R.: Internet-based Expert System. Expert system 7, 129-135 (2000)

4. Mizoguchi, R., Motoda, H.: Expert System Research in Japan. IEEE Intelligent Systems 10, 14-23 (1995)

5. Kozai, T., Hoshi, T.: Intelligent Information Systems for Production Management in Agriculture and Horticulture. Future Generation Computer Systems 5, 131-136 (1989)

6. Nunninen, J.K., Karonen, O.: What Makes Expert Systems Survive Over 10 Years-Empirical Evaluation of several Engineering Applications. Expert System with Applications 24, 199-211 (2003)

7. Roach1, J., Virkar1, R., Drake, C.: An Expert System for Helping Apple Growers. Computers and Electronics in Agriculture 2, 97-108 (1987)

8. Li, D.L., Fu, Z.T., Duan, Y.Q.: Fish-Expert: a Web-based Expert System for Fish Disease Diagnosis. Expert Systems with Applications 23, 311-320 (2002)

9. Lemmon, H.: Comax: An Expert System for Cotton Crop Management. Science New series 233, 29-33 (1986)

10. Jan, S.: Cotton Advice You Can Bank On. Agricultural Research 420, 18-19 (1994) 
11. State 863306 Theme Group: Breakthrough in the Agricultural Expert System Transformation of Traditional Agriculture. Technology Industry 2, 35-37 (2002) (in Chinese)

12. Hua, L., Zhu, Y.W., Luo, Z.: CPMES:Cotton Production Management Expert System Design and Implementation. Process and Application of Small Computers 5, 79-83 (1996) (in Chinese)

13. Liang, M.J.: BP Neural Network Based Diagnosis System for Cotton Pests. Microelectronics and Computer 3, 35-38 (1996) (in Chinese)

14. Feng, X.D., Chen, F.: Diseases Diagnosis of Neural Network Expert System Design and Implementation. Computer Application 17, 42-44 (1997) (in Chinese)

15. Zhang, H.Z., Zhu, Y., Cao, W.X.: Based on Knowledge Model of the Cotton Decision Support System. Cotton Science 17, 201-207 (2005) (in Chinese)

16. Wang, H.J., Lu, X.: Cotton Fertilization Expert System Using GIS Technology in Xinjiang Region. XingJiang Agricultural Sciences 45, 51-56 (2008) (in Chinese)

17. Liu, M.H., Shen, Z.R., Gao, L.W.: Expert System Based on WebGIS for Forecast and Prediction of Agricultural Pests. Transactions of the Chinese Society of Agricultural Machinery 7, 180-186 (2009) (in Chinese) 